\title{
SELECTION OF HEAT TREATMENT FOR ATI 718PLUS CASTING
}

\author{
Oscar Caballero Ruiz ${ }^{1}$, Natalia Soldevilla ${ }^{1}$ \\ ${ }^{1}$ Industria de Turbo Propulsores, S. A.; \\ Edificio no. 300, Parque Tecnológico, Zamudio 48170, Vizcaya, Spain
}

Keywords: 718Plus, casting, heat treatment.

\begin{abstract}
Alloy 718Plus has been developed in recent years and is already available in wrought form, in which several products are already in service. Further developments led to having a cast version of the alloy also ready, with a chemical composition range quite closed since a couple of years ago. Based on this range, the next step to establish a material standard is to fix the heat treatment to be applied. In this case, talking about castings, the whole heat treatment sequence would include homogenization, hot isostatic pressing (HIP), solution and ageing steps.

In this study, different times and temperatures were tried for some of these heat treatment steps, and evaluation was completed on the heat treatment test samples to determine which of the applied heat treatments achieved the most suitable set of mechanical properties. Microstructural evaluation was performed on the test material in order to decide the final heat treatment, with mechanical tests due in short term.
\end{abstract}

\section{Introduction}

ATI Allvac started a few years ago the search for development of a new alloy with increased operating temperature capabilities over widely used Inconel 718. The first trials focused on minor chemical composition changes, trimming $\mathrm{P}$ and $\mathrm{B}$ contents, and by that time the 718ER (Extended Range) alloy was introduced [1]. Later on, the more intensive effort US government funded MAI (Metals Affordability Initiative) program resulted in making ATI 718Plus alloy available in the market, but primarily in its wrought form. Fostered by the interest of aeroengine companies, the casting version of the alloy was also developed, and the chemical composition of this form fixed, as presented in the 718 alloy symposium in 2010 [2]. Further to this, the MAI investigation also researched on the selection of a suitable heat treatment for this cast alloy [3].

The study presented herein focuses on the tuning of the heat treatment of the alloy. Some heat treatment parameters have been investigated, and the effect of their variation on microstructure and assessed, with mechanical tests due in short term. As considerations were taken of likely use of these casting bits in more complex fabrications (a typical situation already reported in literature [4]), where the wrought form would also be present, this study was dedicated to the first steps of the heat treatment. In these first steps the casting bits of those complex fabrications are still individual pieces and their heat treatment is not determined by being welded together to other wrought bits. Homogenization and solution were thus included in the study, whilst ageing heat treatment was considered as a fixed parameter given by the standard wrought specification, which is $788^{\circ} \mathrm{C}$ during 8 hours plus $704^{\circ} \mathrm{C}$ during another additional 8 hours. HIP was not included as such because of lacking of adequate vessel, and also because the shrinkage healing 
effect was not considered, but just the homogenization one, which would be of course covered by the homogenization step in a similar way.

At the same time, some trial parts were produced at PCB to investigate castability features of the new alloy. A demonstration part was produced, using the new alloy as manufacturing material. To easily allow a back to back comparison with the industry baseline 718 alloy, a component currently manufactured in this alloy was selected and the resulting component further evaluated.

The research leading to these results has received funding from the European Union Seventh Framework Programme (FP7) through the LEMCOTEC project under grant agreement number 283216.

\section{Material}

The material used for these trials was produced in a couple of heats by Ross\&Catherall in Sheffield, UK, under permission of ATI Allvac, holder of the patent for this cast alloy. Remelt stock was sent over to a couple of foundries: CPP City of Industry, USA (this provided by GKN, also partner in the LEMCOTEC project, under which scope this work was performed), and PCC France, for production of cast plates on which the heat treatment trials were performed; and PCB, where the demonstration parts were produced.

Final chemical composition of the material is shown in Table 1 below. This chemical composition was determined from available literature, articles presented in the previous 718 alloy and derivatives symposium, in 2010 in Pittsburgh [2], and in Superalloys 2012 Conference [3]. From those reported compositions, a target was established and finally plates were produced at the two selected foundries with the chemical composition shown in Table 1.

Table 1. Chemical composition of used material.

\begin{tabular}{|c|c|c|c|c|c|c|c|c|c|c|c|c|c|}
\hline Element & Cast & $\mathrm{Ni}$ & $\mathrm{Cr}$ & $\mathrm{Co}$ & Mo & W & $\mathrm{Nb}$ & $\mathrm{Al}$ & $\mathrm{Ti}$ & $\mathrm{Fe}$ & $\mathrm{C}$ & $\mathrm{P}$ & $\mathrm{B}$ \\
\hline & $\begin{array}{l}\text { CPP } \\
\text { pieces }\end{array}$ & $\mathrm{Bal}$ & 20,5 & 8,3 & 2,7 & 1 & 6,3 & 1,5 & 0,8 & 9,7 & 0,05 & 0,008 & 0,005 \\
\hline $\begin{array}{c}\text { Weight } \\
\%\end{array}$ & $\begin{array}{c}\text { PCC } \\
\text { France } \\
\text { and } \\
\text { PCB } \\
\text { pieces }\end{array}$ & Bal & 18,8 & 9,41 & 2,62 & 1,18 & 6,48 & 1,59 & 0,78 & 9,2 & 0,067 & 0,006 & 0,005 \\
\hline
\end{tabular}

The material from one heat was used at CPP for producing flat plates, size $300 \times 60 \times 13 \mathrm{~mm}$, see Figure 1 below. 
Figure 1: Used cast plates from CPP, City of Industry, USA.

The material from the other heat was used at PCCF for producing flat plates, size $400 \times 100 \times 20$ $\mathrm{mm}$, see Figure 2 below. Both were then assessed and heat treated as described afterwards.

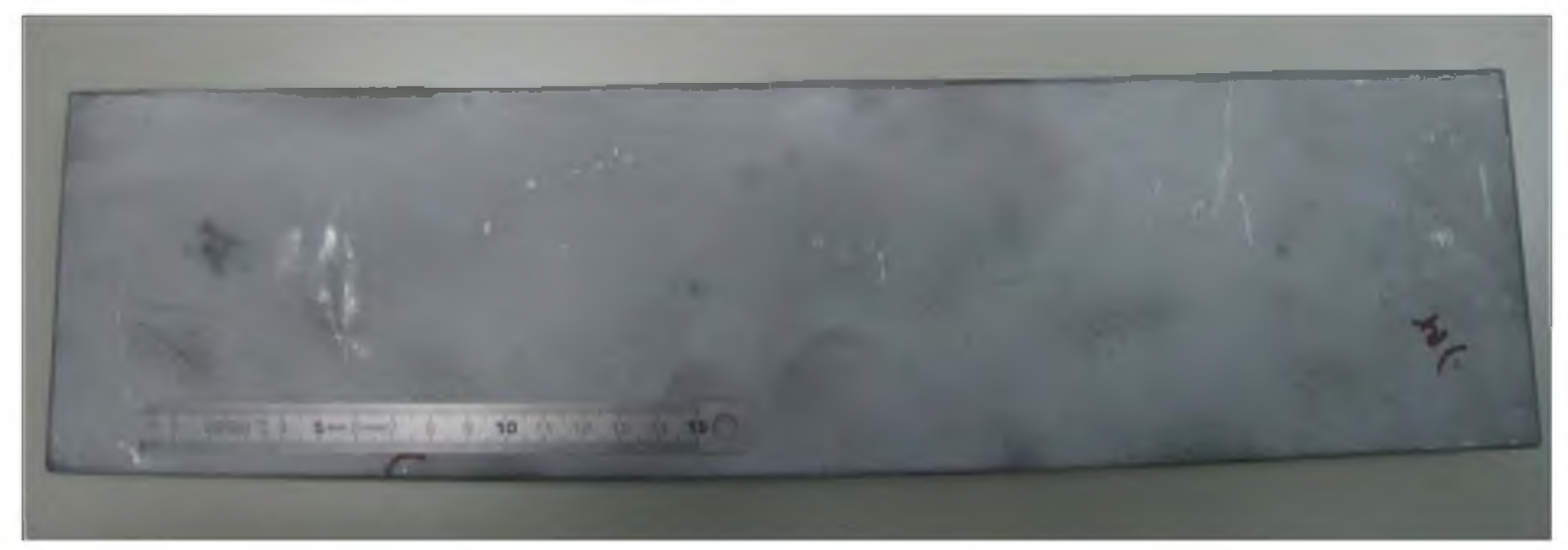

Figure 2: Used cast plates from PCC France

\section{Experimental procedure}

The cast pieces were cut for metallographic assessment and then heat treated to the different parameters as in Tables 2 and 3. Both the as-cast condition and final condition were assessed. The reasons for selecting these heat treatment parameters for the trials were as follow:

A first set of trials was performed following the parameters in Table 2 on the CPP castings. It was decided to apply a single homogenization treatment to the material, which would be equivalent with regard to its effect on microstructure to the shrinkage closure HIP process Separate homogenization treatments were disregarded based on previous published results [3]. Initially, different homogenization temperatures and times were considered. These included $1120^{\circ} \mathrm{C}, 1160^{\circ} \mathrm{C}$, and $1190^{\circ} \mathrm{C}$, and 4,8 , and 24 hours. The times and temperatures were chosen based on literature review, industrial practices and standards, and engineering judgement.

For solution treatment, two temperatures were originally tested; these were $968^{\circ} \mathrm{C}$ and $954^{\circ} \mathrm{C}$. Previous information from literature [3] also considered this range as the optimal one. Finally, the aging heat treatment was chosen as the standard one for wrought material. This was decided in order to avoid a larger extension of the testing plan, and also for the practical reason of manufacturing assemblies which include wrought bits, wherein the ageing heat treatment is already established in the AMS specification 
After initial assessment of these first trials, a narrower selection was made for the trials on the plates cast at PCCF. Only two temperatures $\left(1120^{\circ} \mathrm{C}\right.$ and $\left.1160^{\circ} \mathrm{C}\right)$ and times $(4$ and 8 hours $)$ were selected now as variables for the first step of the heat treatment, based on the most common cycles at heat treating subcontractor and results so far in the previous trials. The rest of times and temperatures tested in preliminary trials for studying the effect of these parameter variation were disregarded. This was based in part on the negligible differences found for these other parameters; and in part on the cost and scheduling benefits of using these more commonly used temperatures within industry.

In order to reduce the test plan for the PCCF plates and again based on the first results, only the $968^{\circ} \mathrm{C}$ solution temperature was finally included for final tests, as this is still in the range of AMS specification for wrought material. As the cast bits are in several occasions used as pieces to be subsequently welded in larger fabrications also including wrought bits, and the final solution heat treatment applied to these fabrications is of course the same to the whole bit, the available range for the cast bits will be the same that the one for the wrought ones.

Finally, following the same reasons, the aging heat treatment was chosen as the standard one.

Table 2: Heat treatment parameters for trials on CPP cast material.

\begin{tabular}{|c|c|}
\hline Treatment & Conditions \\
\hline \multirow{4}{*}{ Homogenization } & $1120^{\circ} \mathrm{C}, 4 \mathrm{~h}$ \\
\cline { 2 - 2 } & $1160^{\circ} \mathrm{C}, 4 \mathrm{~h}$ \\
\cline { 2 - 2 } & $1190^{\circ} \mathrm{C}, 4 \mathrm{~h}$ \\
\cline { 2 - 2 } & $1120^{\circ} \mathrm{C}, 8 \mathrm{~h}$ \\
\cline { 2 - 2 } & $1160^{\circ} \mathrm{C}, 8 \mathrm{~h}$ \\
\cline { 2 - 2 } & $1190^{\circ} \mathrm{C}, 8 \mathrm{~h}$ \\
\cline { 2 - 2 } Solution & $1120^{\circ} \mathrm{C}, 24 \mathrm{~h}$ \\
\cline { 2 - 2 } & $1190^{\circ} \mathrm{C}, 24 \mathrm{~h}$ \\
\hline \multirow{3}{*}{ Precipitation } & $954^{\circ} \mathrm{C}$ \\
& $968^{\circ} \mathrm{C}$ \\
\hline \multirow{3}{*}{} & $788^{\circ} \mathrm{C}, 8 \mathrm{~h}$, \\
& Furnace $\mathrm{cool}: 50^{\circ} \mathrm{C} / \mathrm{h}$ to $704^{\circ} \mathrm{C}$ \\
& $704^{\circ} \mathrm{C}, 8 \mathrm{~h}$ \\
\hline
\end{tabular}

Table 3: Heat treatment parameters for trials on PCCF cast material.

\begin{tabular}{|c|c|}
\hline Treatment & Conditions \\
\hline \multirow{3}{*}{ Homogenization } & $1120^{\circ} \mathrm{C}, 4 \mathrm{~h}$ \\
\cline { 2 - 2 } & $1160^{\circ} \mathrm{C}, 4 \mathrm{~h}$ \\
\cline { 2 - 2 } & $1120^{\circ} \mathrm{C}, 8 \mathrm{~h}$ \\
\cline { 2 - 2 } Solution & $1160^{\circ} \mathrm{C}, 8 \mathrm{~h}$ \\
\hline \multirow{3}{*}{ Precipitation } & $968^{\circ} \mathrm{C}, 1 \mathrm{~h}$ \\
\hline & $788^{\circ} \mathrm{C}, 8 \mathrm{~h}$, \\
& Furnace $\mathrm{cool}: 50^{\circ} \mathrm{C} / \mathrm{h}$ to $704^{\circ} \mathrm{C}$ \\
& $704^{\circ} \mathrm{C}, 8 \mathrm{~h}$ \\
\hline
\end{tabular}


Variations in microstructure resulting from these heat treatments were assessed through optical microscopy and hardness measurements. Some additional differences were observed in the samples depending on the particular location from which they were taken. For example, samples close to the outer surface presented fine grain sizes and small SDAS, whilst samples located closer to the feeding system showed much larger grain size and SDAS. However, this variation was minimized from the present study by controlling specimen location.

Samples were ground, polished and etched with Kallings reagent 2. Finally, hardness measurements were carried out using the Brinell method.

\section{Results}

\section{$\underline{\text { Microstructure }}$}

The Figures below show the different microstructures observed with the applied heat treatments. Grain size and SDAS were also measured, but these were not considered to be relevant to the aim of the heat treatment study. Although SDAS could influence the kinetics of the heat treatment, its relative effects would be the same regardless the applied heat treatment parameters.

Results in the as-cast conditions are shown in Figures 3 and 4 at different magnifications $(\times 50$, $\times 200$, and $\times 500$ ).

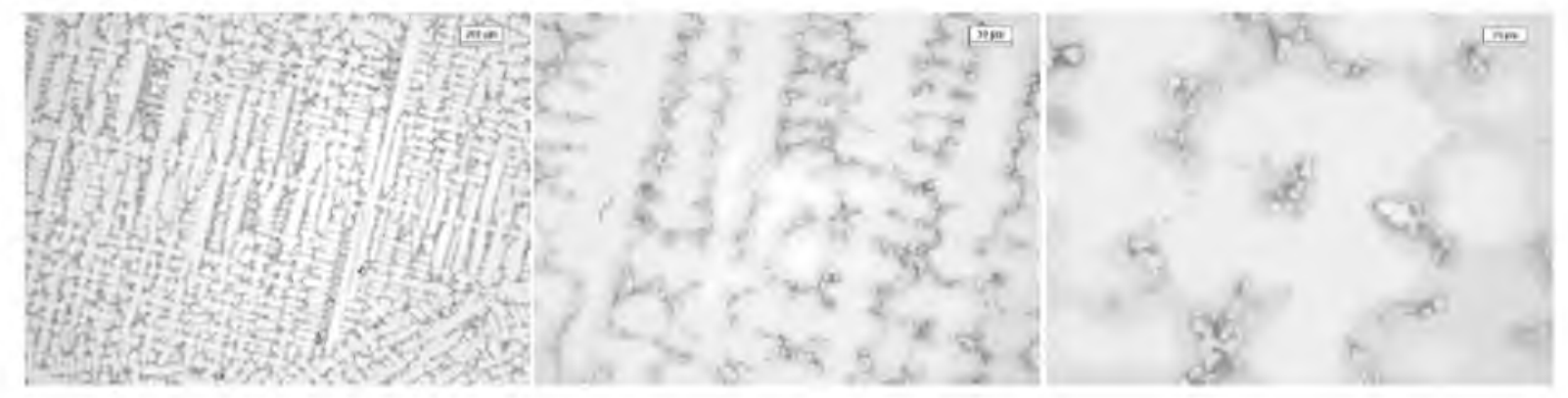

Figure 3: As cast condition of ATI 718Plus pieces produced at CPP.

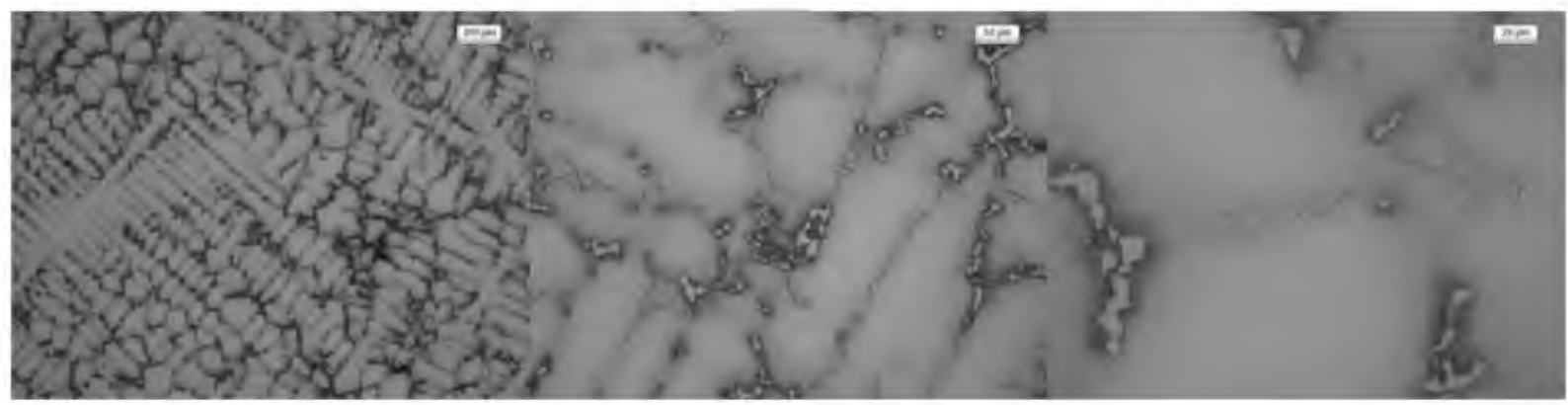

Figure 4: As cast condition of ATI 718Plus pieces produced at PCCF.

Figures $5 \mathrm{a}-\mathrm{d}$ and $6 \mathrm{a}-\mathrm{d}$ show the structures at the same magnifications for the heat treated material produced at CPP and PCCF, respectively. Out of the 16 conditions tested on the CPP plates, the four conditions deemed the most interesting, considering evolution and/or development of microstructures and their response to heat treatment. 


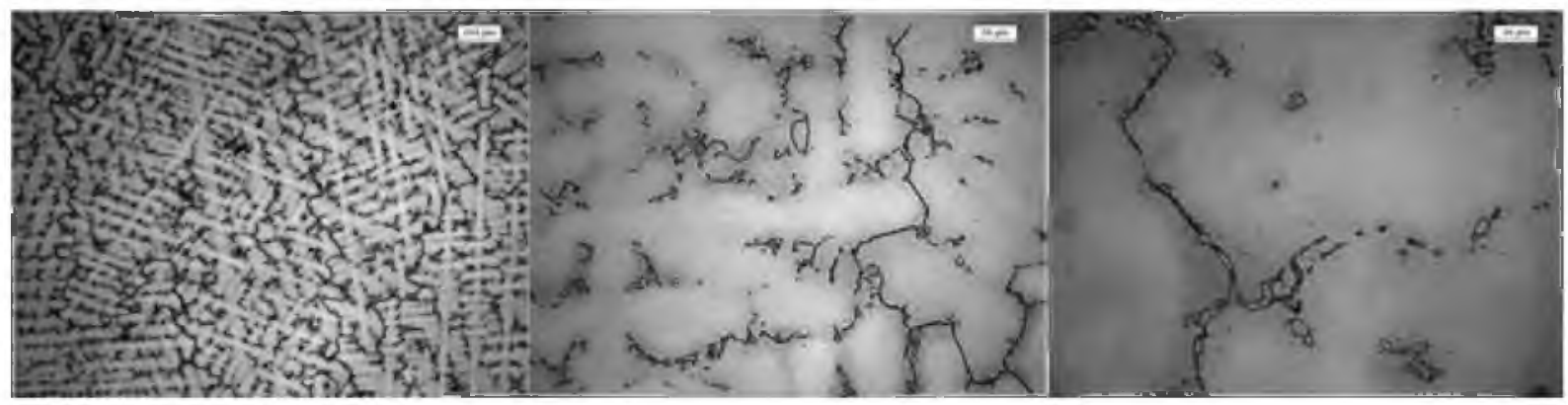

Figure 5a: Final condition of ATI 718Plus pieces produced at CPP. Homogenization $1120^{\circ} \mathrm{C}, 4 \mathrm{~h}$, solution $954^{\circ} \mathrm{C}, 1 \mathrm{~h}$.

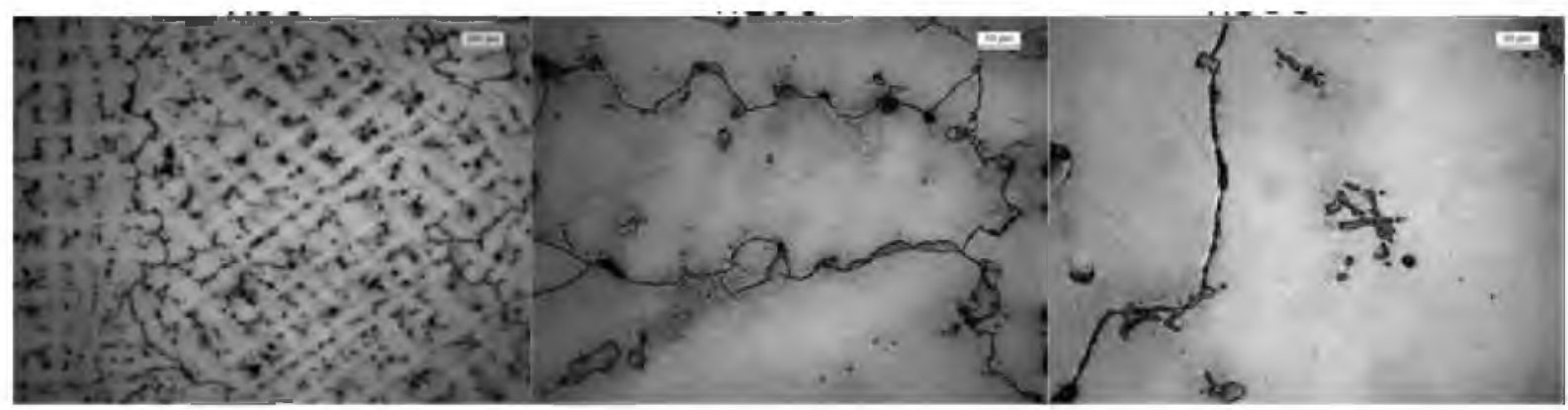

Figure 5b: Final condition of ATI 718Plus pieces produced at CPP. Homogenization $1190^{\circ} \mathrm{C}, 4 \mathrm{~h}$, solution $954^{\circ} \mathrm{C}, 1 \mathrm{~h}$.

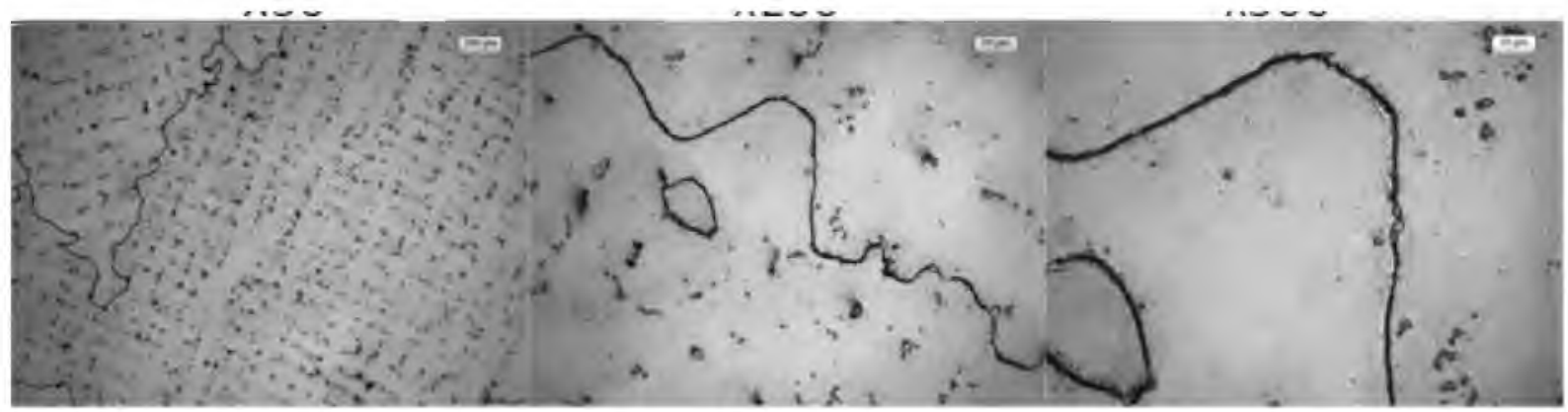

Figure 5c: Final condition of ATI 718Plus pieces produced at CPP. Homogenization $1160^{\circ} \mathrm{C}, 8 \mathrm{~h}$, solution $968^{\circ} \mathrm{C}, 1 \mathrm{~h}$.

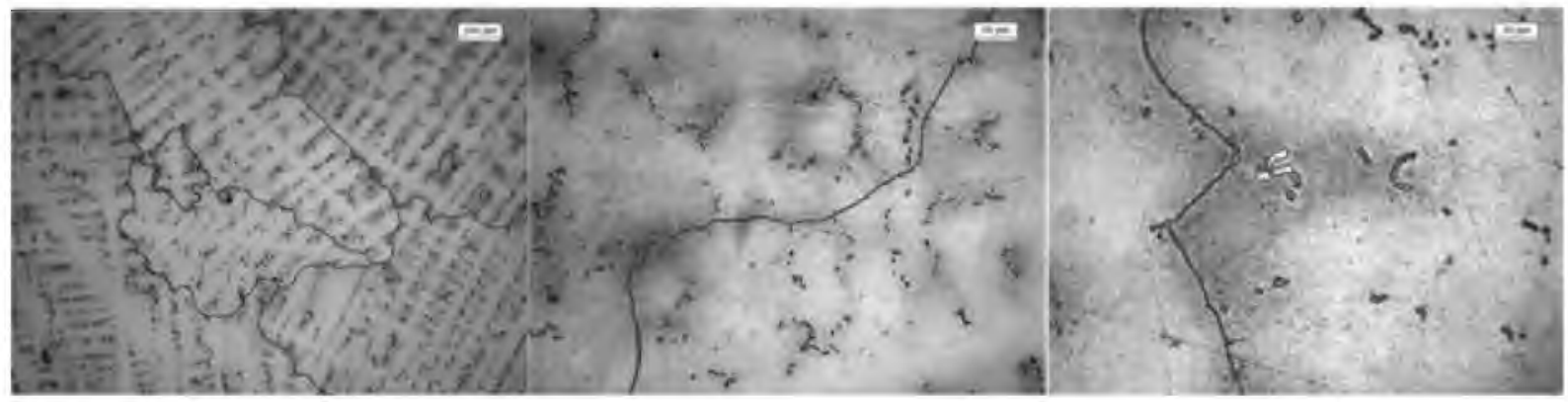

Figure 5d: Final condition of ATI 718Plus pieces produced at CPP. Homogenization $1120^{\circ} \mathrm{C}, 24 \mathrm{~h}$, solution $954^{\circ} \mathrm{C}, 1 \mathrm{~h}$. 


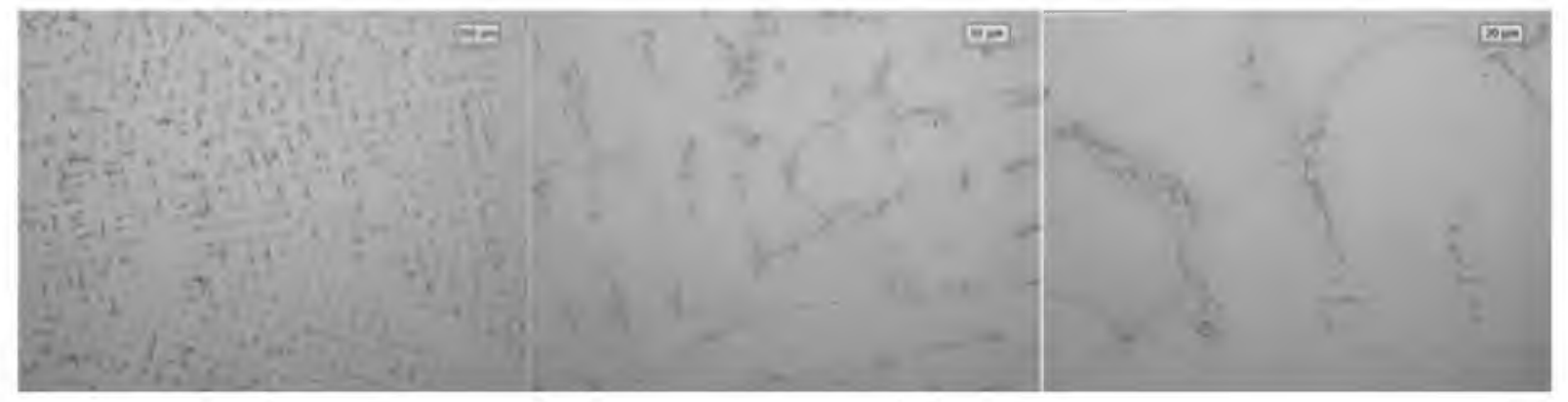

Figure 6a: Final condition of ATI 718Plus pieces produced at PCCF. Homogenization $1120^{\circ} \mathrm{C}, 4 \mathrm{~h}$, solution $968^{\circ} \mathrm{C}, 1 \mathrm{~h}$.

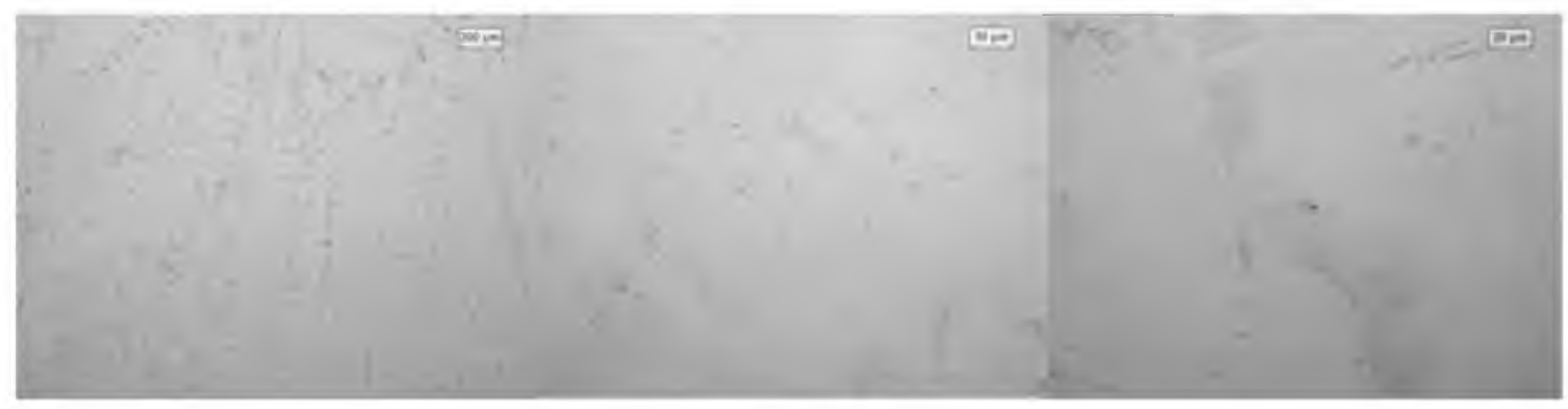

Figure 6b: Final condition of ATI 718Plus pieces produced at PCCF.

Homogenization $1160^{\circ} \mathrm{C}$, $4 \mathrm{~h}$, solution $968^{\circ} \mathrm{C}, 1 \mathrm{~h}$.

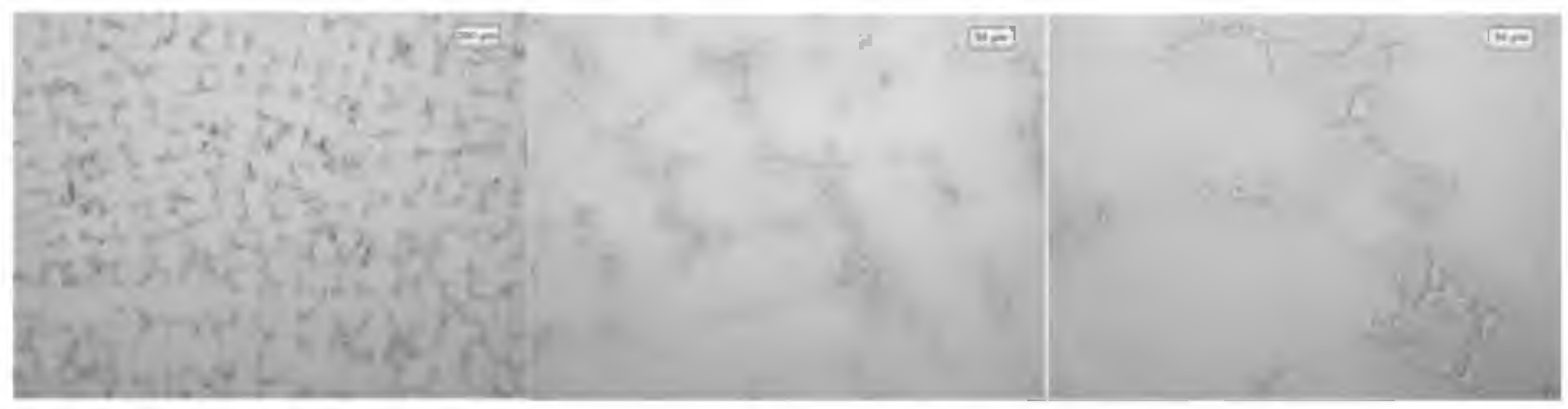

Figure 6c: Final condition of ATI 718Plus pieces produced at PCCF.

Homogenization $1120^{\circ} \mathrm{C}, 8 \mathrm{~h}$, solution $968^{\circ} \mathrm{C}, 1 \mathrm{~h}$.

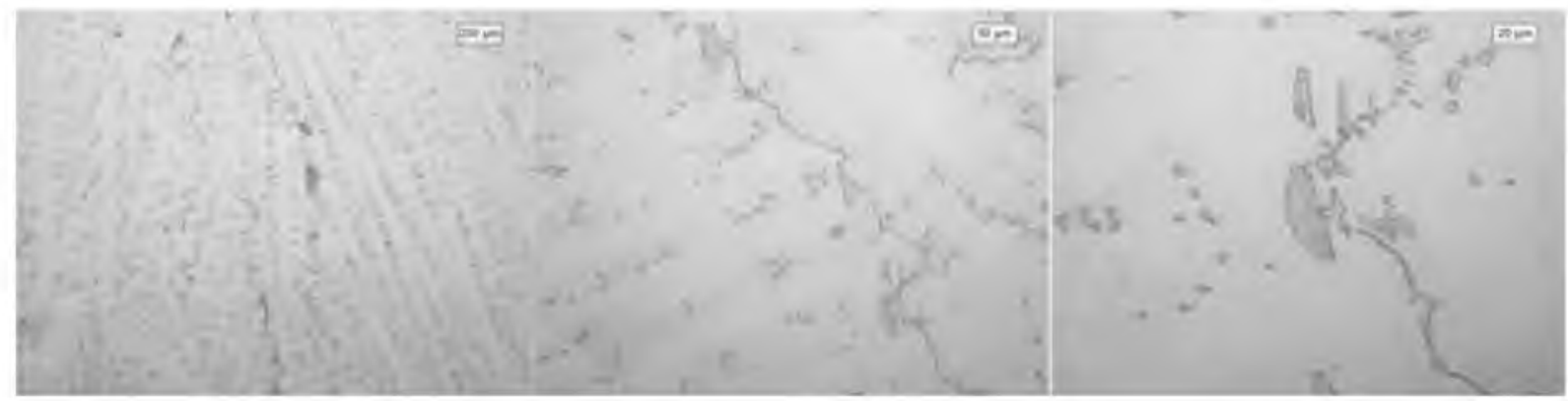

Figure 6d: Final condition of ATI 718Plus pieces produced at PCCF. Homogenization $1160^{\circ} \mathrm{C}, 8 \mathrm{~h}$, solution $968^{\circ} \mathrm{C}, 1 \mathrm{~h}$. 


\section{$\underline{\text { Hardness }}$}

Brinell macrohardness testing was performed on the different bits in the final aged condition, with the following results obtained, as shown in Tables 4 and 5:

Table 4. Hardness measurements on the CPP cast samples.

\begin{tabular}{|c|c|}
\hline $\begin{array}{c}\text { Heat treat trial parameters: } \\
\text { Homogenisation / Solution }\end{array}$ & $\begin{array}{c}\text { Hardness HB } \\
\text { (max, min) or avg. }\end{array}$ \\
\hline As cast & 338 \\
\hline $1120^{\circ} \mathrm{C}, 4 \mathrm{~h} / 954^{\circ} \mathrm{C}, 1 \mathrm{~h}$ & 402,404 \\
\hline $1120^{\circ} \mathrm{C}, 4 \mathrm{~h} / 968^{\circ} \mathrm{C}, 1 \mathrm{~h}$ & 402,405 \\
\hline $1160^{\circ} \mathrm{C}, 4 \mathrm{~h} / 954^{\circ} \mathrm{C}, 1 \mathrm{~h}$ & 404,397 \\
\hline $1160^{\circ} \mathrm{C}, 4 \mathrm{~h} / 968^{\circ} \mathrm{C}, 1 \mathrm{~h}$ & 391,390 \\
\hline $1190^{\circ} \mathrm{C}, 4 \mathrm{~h} / 954^{\circ} \mathrm{C}, 1 \mathrm{~h}$ & 392,391 \\
\hline $1190^{\circ} \mathrm{C}, 4 \mathrm{~h} / 968^{\circ} \mathrm{C}, 1 \mathrm{~h}$ & 394,393 \\
\hline $1120^{\circ} \mathrm{C}, 8 \mathrm{~h} / 954^{\circ} \mathrm{C}, 1 \mathrm{~h}$ & 406,397 \\
\hline $1120^{\circ} \mathrm{C}, 8 \mathrm{~h} / 968^{\circ} \mathrm{C}, 1 \mathrm{~h}$ & 388,407 \\
\hline $1160^{\circ} \mathrm{C}, 8 \mathrm{~h} / 954^{\circ} \mathrm{C}, 1 \mathrm{~h}$ & 388,399 \\
\hline $1160^{\circ} \mathrm{C}, 8 \mathrm{~h} / 968^{\circ} \mathrm{C}, 1 \mathrm{~h}$ & 388,389 \\
\hline $1190^{\circ} \mathrm{C}, 8 \mathrm{~h} / 954^{\circ} \mathrm{C}, 1 \mathrm{~h}$ & 391,392 \\
\hline $1190^{\circ} \mathrm{C}, 8 \mathrm{~h} / 968^{\circ} \mathrm{C}, 1 \mathrm{~h}$ & 400,389 \\
\hline $1120^{\circ} \mathrm{C}, 24 \mathrm{~h} / 954^{\circ} \mathrm{C}, 1 \mathrm{~h}$ & 398 \\
\hline $1120^{\circ} \mathrm{C}, 24 \mathrm{~h} / 968^{\circ} \mathrm{C}, 1 \mathrm{~h}$ & 402 \\
\hline $1190^{\circ} \mathrm{C}, 24 \mathrm{~h} / 954^{\circ} \mathrm{C}, 1 \mathrm{~h}$ & 389 \\
\hline $1190^{\circ} \mathrm{C}, 24 \mathrm{~h} / 968^{\circ} \mathrm{C}, 1 \mathrm{~h}$ & 395 \\
\hline
\end{tabular}

Table 5. Hardness measurements on the PCCF cast samples.

\begin{tabular}{|c|c|}
\hline $\begin{array}{c}\text { Heat treat trial parameters: } \\
\text { Homogenisation }\end{array}$ & $\begin{array}{c}\text { Hardness HB } \\
\text { (max, min) or avg. }\end{array}$ \\
\hline As cast & 341 \\
\hline $1120^{\circ} \mathrm{C}, 4 \mathrm{~h}$ & 384 \\
\hline $1160^{\circ} \mathrm{C}, 4 \mathrm{~h}$ & 383 \\
\hline $1120^{\circ} \mathrm{C}, 8 \mathrm{~h}$ & 390 \\
\hline $1160^{\circ} \mathrm{C}, 8 \mathrm{~h}$ & 372 \\
\hline
\end{tabular}

\section{Discussion}

\section{$\underline{\text { Microstructure }}$}

Observation of the microstructures showed that the lower solution temperature did not cause any grain boundary precipitation such as delta to occur. As this is desirable for improving the high temperature and creep resistance, the selected solution temperature was finally the $968^{\circ} \mathrm{C}$ one. Additionally, this temperature is in the center of the AMS specification range $\left(954\right.$ to $\left.982^{\circ} \mathrm{C}\right)$ for this treatment. 
Regarding homogenization, it was noticed that the application of the lowest temperature in preliminary trials did not completely dissolve the Laves phases that were present in the as-cast condition material. However, the replication of these heat treatments was considered of interest for confirming that this temperature is not sufficient to dissolve completely the Laves phases and does not achieve a homogeneous solid solution.

It was later clearly noticed when comparing Figures $6 \mathrm{a}$ and $6 \mathrm{~b}$ that the higher homogenization temperature resulted in much more effective reduction of Laves phases. The sizes of these segregations were smaller and also the delta needles around them resulting from the diffusion of the available $\mathrm{Nb}$ were not as noticeable. A detailed example is shown in Figure 7.

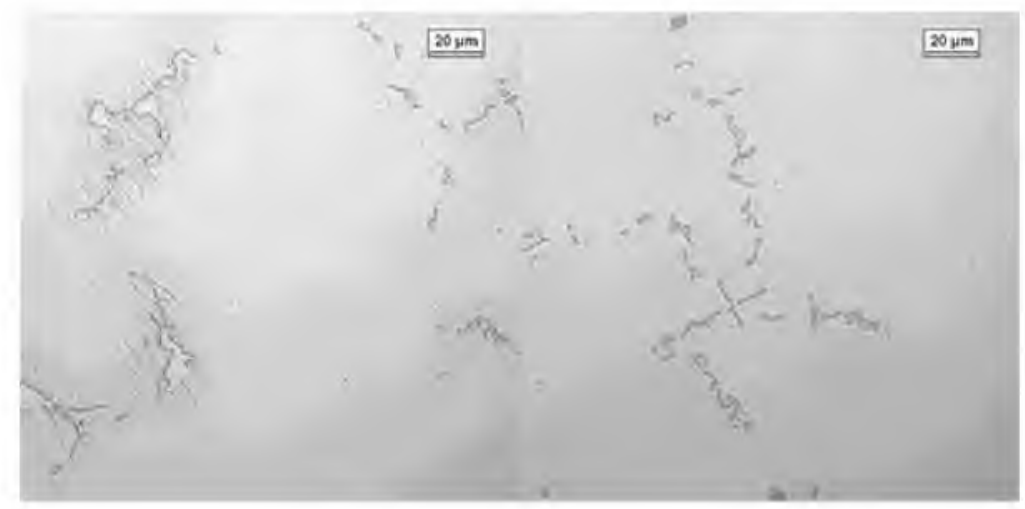

Figure 7: Comparison of Laves phase occurrence. Left, $1120^{\circ} \mathrm{C}, 4$ hours; right, $1160^{\circ} \mathrm{C}, 4$ hours.

Additionally, the effect of time is also perceived in the tested samples when testing at $1120^{\circ} \mathrm{C}$. It was noticed that increasing the treatment time from 4 to 8 hours resulted in lower amount of Laves phases. At the same time, available $\mathrm{Nb}$ in those segregations was diffused resulting in a surrounding area of delta needles, as shown in Figure 8.

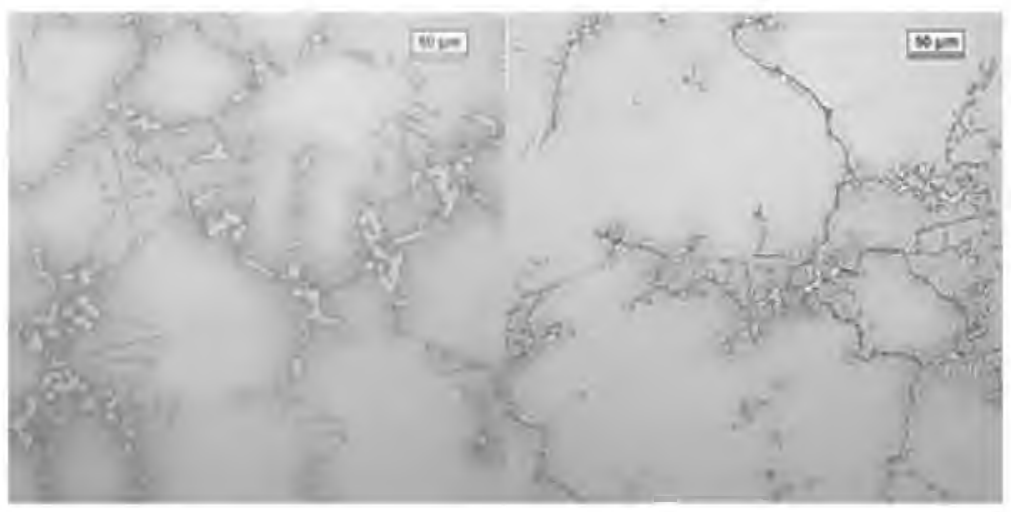

Figure 8: Comparison of Laves and delta phases occurrence. Left, $1120^{\circ} \mathrm{C}, 4$ hours; right, $1120^{\circ} \mathrm{C}, 8$ hours. 


\section{$\underline{\text { Hardness }}$}

Regarding hardness, it was difficult to obtain any conclusions. The recorded measurements showed very stable values, with little scatter regardless the applied heat treatment parameters. The values shown in Tables 4 and 5 show that variation of these values is mostly below $5 \%$, which is low enough so as not to derive any conclusions of important changes because of the heat treat parameters variation.

\section{Demonstration part}

At the same time of producing the plates, a demonstration part was produced to assess the capability of the alloy for casting. For this purpose, it was decided to use an already existing geometry which would ease the direct comparison with current 718 alloy. A component was chosen and alloy replaced by the new ATI 718Plus material. As a starting point, and following foundry experience, it was decided not to modify any of the casting parameters (such as pouring temperature or gating design), despite some discussions with peers and experts in casting processes to trim them.

Results obtained on the part were completely satisfactory. Major defects such as misruns or others were not detected, as can be seen in the photograph of the component shown in Figure 9. Moreover, the different inspections of the part didn't show any defect or discontinuity that might be attributed to the change of alloy. On the contrary, typical casting defects such as shrinkages were not detected, using FP or X-Ray inspections. This trial allowed us to gain confidence in the good behavior of the alloy for casting.

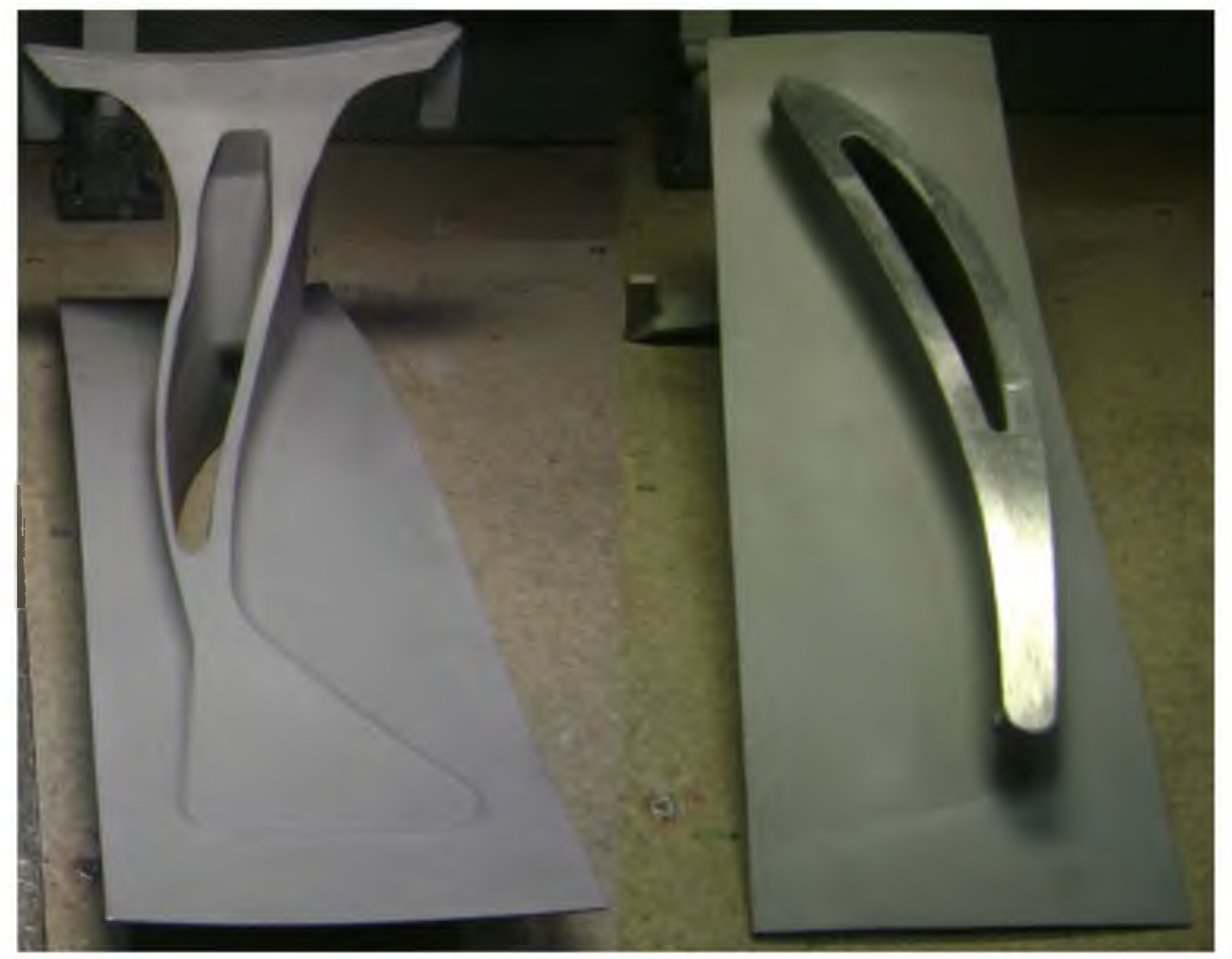

Figure 9: Photographs of demonstration part in ATI 718Plus produced at PCB. 


\section{Future work}

The work described herein was part of the European LEMCOTEC R\&D program. Additional assessment of these heat treat trials is planned with the completion of mechanical tests, to be performed.

Also, an additional demonstration part, more complex than the one already produced, is planned to be poured shortly,

\section{Conclusions}

- Application of higher homogenization temperatures (around $1160^{\circ} \mathrm{C}$ ) is advised if lower segregations in the cast microstructure are desired. This allows full dissolution of $\mathrm{Nb}$, which makes it then available for subsequent formation of the hardening phase. It is assumed that this will also improve the mechanical properties, something which will be verified through mechanical testing.

- Solution heat treatment temperature selected for casting is $968^{\circ} \mathrm{C}$. This allows certain amount of delta phase to appear at the grain boundaries, which should improve the high temperatures and creep rupture properties.

- The alloy shows good castability characteristics, at least similar to regular 718 alloy. No major defects on a trial part were detected because of change of the alloy, with no other casting parameter modified.

\section{References}

1. W.D. Cao, R.L. Kennedy, "Thermal Stability of Alloys 718 and ALLVAC 718-ER®", Superalloys 718, 625, 706 and Various Derivatives Symposium, Pittsburgh, PA, USA, 2001.

2. B. Peterson, V. Krishnan, et al. "Castability of 718Plus for Structural Gas Turbine Engine Components," 7th International Symposium on Superalloy 718 \& Derivatives. TMS, 2010.

3. B. Peterson et al. "On the Development of Cast ATI 718Plus $®$ Alloy for Structural Gas Turbine Engine Components"; Superalloys 2014 Conference. TMS, 2012.

4. G. Sjöberg "Casting Superalloys for Structural Applications", 7th International Symposium on Superalloy 718 \& Derivatives. TMS, 2010.

5. J. Andersson, G. Sjöberg, J. Larsson, "Investigation of Homogenization and its Influence on the Repair Welding of Cast Allvac 718Plus Superalloy", 7th International Symposium on Superalloy 718 \& Derivatives. TMS, 2010. 